\title{
The effects of intergroup context of evaluation on ambivalence toward the ingroup and the outgroup
}

\author{
ANGELICA MUCCHI-FAINA ${ }^{1 *}$, \\ SANDRO COSTARELLI ${ }^{2}$ and CHIARA ROMOLI ${ }^{1}$ \\ ${ }^{1}$ Università di Roma 'La Sapienza', Italy \\ ${ }^{2}$ Università di Bologna, Italy
}

\begin{abstract}
A study is reported which examines the relations between ambivalence toward the ingroup and the outgroup. The basic assumption was that ambivalent attitudes in intergroup contexts contribute to satisfying two competing motivations of group members, i.e. establishment of positive distinctiveness for the ingroup and conformity to the fairness norm. Participants were asked to evaluate the ingroup and one other group by using unipolar (positively and negatively valenced) affect-and cognitionbased items. We predicted an interaction effect of target group (ingroup versus outgroup) and attitude domain (affect-based versus cognition-based) on ambivalence. Additional hypotheses were formulated taking separately into account the positive and the negative unipolar items. We expected that on positively valenced items the ingroup would be favoured over the outgroup on both affect-and cognition-based evaluations. Besides, we predicted that on negatively valenced items, the ingroup would be favoured over the outgroup on affect-based evaluation but not on cognition-based evaluation. Results indicated support for the predictions and shed light on the moderating role played by attitude domains on both ambivalence and ingroup favouritism. Copyright (C) 2002 John Wiley \& Sons, Ltd.
\end{abstract}

Past research has shown that responses to a social target can be internally inconsistent, thus resulting in an ambivalent (i.e. positively and negatively valenced) rather than univalent attitude (positively or negatively valenced; for review and discussion, see Eagly \& Chaiken, 1993). As regards adding insight into attitudinal structure, the investigation of ambivalence can help illuminate various phenomena (Cacioppo \& Berntson, 1994), such as attitude accessibility (e.g. Bargh, Chaiken, Govender, \& Pratto, 1992) and stability (e.g. Pomerantz, Chaiken, \& Tordesillas, 1995), resistance to persuasive information (e.g. Crano \& Sivacek, 1984), the relation between attitudes and behavioural intentions (e.g. Jonas, Diehl, \& Bromer, 1997), behavioural responses (e.g. Katz, Wackenhut, \& Hass, 1986), information processing (e.g. Maio, Bell, \& Esses, 1996), minority influence (e.g. Mucchi-Faina, 2000) and interindividual relationships (for a review, see Thompson \& Holmes, 1996).

*Correspondence to: Angelica Mucchi-Faina, Facoltà di Lettere, Università di Chieti, via dei Vestini 31, 66013 Chieti, Italy. E-mail: ssmucchi@unipg.it

Contract grant sponsor: MURST

Copyright (C) 2002 John Wiley \& Sons, Ltd.

Received 29 May 2000

Accepted 22 March 2001 
Although the concept of attitudinal ambivalence was originally developed in the general attitudes domain (Kaplan, 1972; Scott, 1966, 1969), most researchers have employed this construct to study ambivalence toward various social groups (e.g. Katz \& Hass, 1988; Thompson \& Zanna, 1995; Thompson, Zanna, \& Griffin 1995; Zanna \& Rempel, 1988) such as African-Americans (e.g. Gaertner \& Dovidio, 1986; Katz et al., 1986; McConahay, 1983; McConahay \& Hough, 1976), Gypsies (e.g. Mucchi-Faina, 'Asymétrie de l'ambivalence envers une minorité: le cas des gitans', unpublished manuscript, 1999), homosexuals (e.g. Haddock, Zanna, \& Esses, 1993), immigrants (e.g. Maio et al., 1996), and women (e.g. Glick, Diebold, Bailey-Werner, \& Zhu, 1997; Glick \& Fiske, 1996; MacDonald \& Zanna, 1998).

Also our research is focused on ambivalence toward social groups. Specifically, the present study tackles three important features of ambivalence. First, we investigate ambivalence not only toward the outgroup, but also toward the ingroup. Although univalent attitudes toward groups have been thoroughly investigated with reference both to the outgroup and the ingroup, ambivalent attitudes toward the ingroup have been the object not only of little research attention (among the few exceptions, Jost \& Burgess, 2000), but also of inconsistent predictions (e.g. Deaux, 1996; Fiske \& Ruscher, 1995; Phinney, 1990).

Second, the present study approaches ambivalence in intergroup contexts with a focus on the effects of group membership on attitude formation. Ambivalence toward social groups has mainly been considered by the past research as an outcome of the individual's (conscious or unconscious) psychological conflict between personal attitudes and personal standards (e.g. Gaertner \& Dovidio, 1986; Monteith, 1993) or as reflecting competing personal values (Katz et al., 1986). In contrast to this research tradition, it is the differential outcome of ambivalence toward the ingroup and the outgroup as a function of group membership-based concerns that sets the stage for this study.

Finally, we explore attitude ambivalence on both cognition- and affect-based dimensions.

\section{COGNITION-BASED VERSUS AFFECT-BASED ATTITUDES}

Our choice to study the cognitive and affective underpinnings of attitudes toward ingroup and outgroup was both theoretically and empirically guided. At the theoretical level, attitudes have often been described as being rooted in three classes of information concerning their object - cognitive (i.e. beliefs), affective (i.e. emotions, moods, and feelings), and behavioural (i.e. past actions or future intentions of specific behavioural acts) (e.g. Breckler, 1984). Besides, and with more specific reference to this paper, in the intergroup processes literature too it has long been argued that intergroup attitudes are multi- rather than unidimensional (e.g. Allport, 1954) - a perspective that recent theories of prejudice have incorporated (for a review, see Duckitt, 1992).

The importance of assessing the relative contribution of components to overall intergroup attitudes has lately been recognised as having societal potentials as well (e.g. Mullen, Brown, \& Smith, 1992). To begin with, since prior research has shown that the component on which an intergroup attitude is most heavily based may determine the behavioural consequences of the latter (e.g. Sears, 1988), knowledge of the crucial component may contribute to intergroup attitudes' change. Because different strategies may prove most fruitful in changing attitudes based on different components (Zanna \& Rempel, 1988), attempts to modify negatively valenced intergroup attitudes may thus usefully be targeted at the critical components of these attitudes.

Our choice of such types of measures was also empirically guided insofar as the study of affect- and cognition-based dimensions of intergroup evaluation has already yielded interesting results in the area of univalent attitudes (e.g. Singh, Mei Choo, \& Li Poh, 1998; Sing, Yeoh, Lim, \& Lim, 1997). 
Intergroup evaluations have been shown to have cognitive and affective components which, although non entirely independent, are often partially non-redundant (e.g. Haddock et al., 1993). Moreover specific target groups may differ in the extent to which they invoke affect- or cognition-based evaluations (Lavine, Thomsen, Zanna, \& Borgida, 1998).

Recently, researchers have also examined affective and cognitive dimensions of attitudinal ambivalence (Thompson et al., 1995). Specifically, ambivalence has been conceptualised in two different ways: (a) as stemming from conflicting evaluations within the dimensions of affect or cognition (simultaneously liking and disliking or, alternatively, approving and disapproving), and (b) as arising from conflicting evaluations between these two dimensions (liking but disapproving or, alternatively, disliking but approving) (Lavine et al., 1998; MacDonald \& Zanna, 1998; Thompson et al., 1995). In the present research we dealt with the former type of attitudinal ambivalence. Accordingly, we exploratively assessed within-dimension affect- and cognition-based ambivalence toward the ingroup and the outgroup.

\section{BIAS, ASYMMETRY AND NORMS IN INTERGROUP EVALUATIONS}

Both theory (Social identity theory: Tajfel \& Turner, 1979; Self-categorisation theory: Turner, 1987) and research (for a review, see Messick and Mackie, 1989) on intergroup processes have highlighted that intergroup evaluations obey the fundamental motive of establishing a positive distinctiveness of the ingroup vis-à-vis relevant outgroups as a strategy for achieving or maintaining a positive social identity. Consequently, people tend to evaluate the ingroup more positively than the outgroup (intergroup bias: for overviews, see Messick \& Mackie, 1989; for a meta-analysis, see Mullen et al., 1992).

In addition to finding strong support for ingroup favouritism, the past research has found that people try not to show their negatively valenced attitudes toward social groups they do not belong to. For example, according to the so-called positive-negative asymmetry hypothesis (Wenzel \& Mummendey, 1996; for a discussion, see Mummendey \& Otten, 1998) ingroup favouritism in a positive dimension is more pronounced than in a negative one, unless certain aggravating conditions are present (see also Dovidio, Gaertner, Isen, Rust, \& Guerra, 1998). One of the current explanations for this asymmetry effect suggests that pro-ingroup differentiation without objective reasons is perceived as inappropriate and in the positive area the lack of justification for unequal intergroup treatment is less visible than in the negative one (Mummendey \& Otten, 1998).

Another way that people try not to show their negative attitudes toward social groups is to attempt systematically to alter their expressed attitudes and behaviours to appear more equalitarian and unprejudiced than they actually are (McConahay, Hardee, \& Batts, 1981). Mackie and Smith (1998) have interpreted this latter process as an effect of people's socially based concerns stemming from their awareness to contradict valued ingroup norms. Expressing non-prejudicial evaluations of outgroups, what is currently meant by 'political correctness' (Barker, 1994) has been assessed as being in line with current social norms (fairness norm: Singh et al., 1998) of both European (Pettigrew \& Meertens, 1995) and North-American (for an overview and discussion, see Fiske, 1998) societies. Consequently, patterns of positive differentiation in natural groups seem to be achieved within the context of social norms.

\section{A POSSIBLE ROLE OF AMBIVALENCE IN INTERGROUP EVALUATION}

Taking the above argument further, several authors have suggested that intergroup evaluation and behaviour are indeed enacted as a compromise between two competing motivations, i.e. maintenance 
of positive ingroup distinctiveness and conformity to the fairness norm (e.g. Bornstein, Crum, Wittenbraker, Harring, Insko, \& Thibaut, 1983a, b; Branthwaite \& Jones, 1975; Singh et al., 1998; Tajfel et al., 1971; Turner, 1983a, b). In line with this theoretical reasoning, we posit that ambivalence toward both the ingroup and the outgroup can function as a compromise strategy to cope with two contrasting motivations insofar as it allows for compliance with the fairness norm without discounting the ingroup. Ambivalence is typically defined as 'a positive as well as a negative evaluation of a given attitude object at the same time' (Jonas et al., 1997, p. 191). Therefore, on the one hand, we argue that ambivalence toward the ingroup can, so to speak, mask ingroup favouritism because positive evaluations are expressed together with some negative ones in order to show the evaluative objectivity that is prescribed by the fairness norm. On the other hand, we would think that ambivalence toward the outgroup softens outgroup derogation, since outgroup-targeting negative evaluations are expressed together with some positive ones in order to show no prejudice (fairness norm). In both cases, therefore, ambivalence can serve the function of attenuating the impact of intergroup bias in favour of normative conformity.

However, these processes would not necessarily be revealed by participants' higher overall ambivalence toward the ingroup rather than the outgroup. We argue that it may be the case that intergroup ambivalence is expressed on different attitude domains according to the target group.

\section{COGNITION AND AFFECT-BASED AMBIVALENCE TOWARD THE INGROUP AND THE OUTGROUP}

Prior research has shown that people can display intergroup bias to a different extent in cognition- and in affect-based responses to the ingroup and to the outgroup (e.g. Judd, Park, Ryan, Brauer, \& Kraus, 1995; Yee \& Brown, 1992; Singh et al., 1998). In fact, all theories of emotion share a representation of affect in terms of such abstract associative structures that cannot easily be accessed (Vescio, Hewstone, Crisp, \& Rubin, 1999). This theoretical tradition has received empirical support by finding that affectbased attitudes are less subject to consistency pressures than cognition-based attitudes (Pettigrew, 1997). In this regard we note that this is one of those cases in which research and common sense agree (see the Italian saying al cuor non si comanda, 'one cannot give orders to one's heart'). As a consequence, we argue that in general affect-based evaluations should be less subject to normative control than cognition-based evaluations. Moreover, there is a further plausible reason to think that in an intergroup context the fairness norm in evaluations of the ingroup is active primarily along the cognitive dimension. Although we have failed to find some empirical results supporting this position, social norms may permit (and sometimes even promote) an affective preference for the ingroup, and in particular for some very affectively involving types of ingroups (e.g. family, nation). Accordingly, in general intergroup bias should be more evident in affect-based evaluations, whereas the fairness norm should impact primarily on the more controllable cognition-based intergroup evaluations. As a consequence, ambivalence should be particularly strong on cognition-based evaluations.

Moreover, in the cognitive area ambivalence should be stronger toward the ingroup rather than the outgroup. In fact, since intergroup bias generally takes form more as ingroup favouritism rather than outgroup derogation (Dovidio et al., 1998), people should express more ambivalence to counterbalance the former rather than the latter.

In contrast, since in the affective domain the evaluation of the ingroup produces high favouritism and low need to control it, affect-based evaluations should be more polarised (and, therefore, less ambivalent) toward the ingroup than it is toward the outgroup. 


\section{OVERVIEW OF THE PROCEDURE AND HYPOTHESES}

In order to investigate this precise issue, in the present study we asked participants to evaluate the ingroup and the outgroup by using affect- and cognition-based attitude items that were both positively and negatively valenced. Following previous suggestions (e.g. Linville, Fischer, \& Salovey, 1989), we adopted a within- rather than a between-participants design in order to evoke maximally in participants the contrasting needs both to preserve positive distinctiveness for the ingroup and to conform to the fairness norm ruling intergroup evaluation.

We predicted no main effect of target group on ambivalence, but rather a difference in the magnitude of ambivalence across the independent variables employed (namely, target group and attitude domain). Specifically, on the basis of the above considerations, we expected that

- cognition-based ambivalence would be stronger toward the ingroup than toward the outgroup, whereas affect-based ambivalence would be greater toward the outgroup than toward the ingroup. Statistically, we thus predicted an interaction of target group (ingroup versus outgroup) and attitude domain (affect-based versus cognition-based) on ambivalence.

In order to find some preliminary support for our interpretation of ambivalence in intergroup context, additional analyses were conducted on ratings expressed on positively and negatively valenced items. Consequently, two additional hypotheses were formulated. Specifically, since ingroup favouritism is more pronounced and less visible in the positive area (Mummendey \& Otten, 1998), we expected that

- when assessing the positively valenced items, the ingroup will be favoured over the outgroup on both affect- and cognition-based evaluations,

- when assessing the negatively valenced items, the ingroup will be favoured over the outgroup on affect-based evaluation (weak activation of the fairness norm) but not on cognition-based evaluation (stronger activation of the fairness norm).

In summary, ingroup favouritism would be expressed above all in the evaluations of the positively valenced items, while the evaluations of the negatively valenced items would be modulated mainly by (stronger or weaker) activation of the fairness norm.

\section{METHOD}

\section{Participants and Overview}

One hundred and sixteen students (78 women, 37 men, 1 unknown; mean age $=19.7$ ) from the University of Rome voluntarily completed a questionnaire during an introductory psychology lecture. They were asked to give their perception of two national groups, their own (i.e. Italians) and one other group on three positive and three negative affect-based items and on three positive and three negative cognition-based items. The order in which the two groups were rated was counterbalanced. Finally, participants were asked to answer two questions about their perceived similarity with the ingroup and the outgroup (manipulation check).

\section{Pilot Study and Design}

Since outgroup features may influence intergroup evaluations, to address potential bias in sampling target outgroups a pilot study checked the selection of four national groups viewed as differing along 
two crucial dimensions, i.e. likeability and relative status (for a discussion on the conceptual relevance of these two constructs, see Glick \& Fiske, in press). Twenty-one undergraduates rated 15 national groups on likeability as viewed by the great majority of Italians $(1=$ not at all, $6=$ extremely) and relative status $(1=$ definitely lower, $6=$ definitely higher $)$. As a result, we selected for the experiment two higher-status outgroups as well as two lower-status outgroups that differ in perceived likeability. ${ }^{1}$

In order to experimentally control for potential confounding main and interaction effects of outgroup's perceived relative status, likeability, and rating order, participants were randomly assigned to one of the eight conditions resulting from the combinations of the target outgroup's perceived status relative to the ingroup (lower, higher), target outgroup's likeability (low, high), and target group rating order (ingroup first, outgroup first). Since preliminary analyses showed that these additional variables did not significantly qualify the main results, data were collapsed across these variables in subsequent analyses.

\section{Dependent Measures}

Attitudes were operationalized as responses to 12 randomly ordered items (six cognition-based and six affect-based; cf. Breckler \& Wiggins, 1989) expressed along a 6-point unipolar scale $(1=$ not at all, $6=$ extremely) with no neutral point. Following Kaplan (1972), this measure was obtained by splitting the typically bipolar semantic differential scales (Osgood, Suci, \& Tannenbaum, 1957) into two unipolar items (cf. MacDonald \& Zanna, 1998). Participants were asked to indicate the degree to which each item fitted their thoughts or feelings toward the group. In this way, separate ranking of positivity (e.g. attraction) and negativity (e.g. aversion) allowed independent assessment of ambivalence within each attitude domain (e.g. allowing for participants' reports that they felt both attraction and aversion towards the group).

In order to select the cognition- and affect-based items, we examined those that have been used in past research (for review and discussion, see Haddock \& Zanna, 1999). As a result, we selected a set of six positively valenced items that seemed appropriate for intergroup evaluation; then, the antonyms to the initial items were identified by using a thesaurus. The 12 items were pre-tested by asking 20 students to rate the extent to which each word appealed to 'emotions and feelings' (i.e. it was affectbased) or to 'thoughts and pieces of information' (i.e. it was cognition-based) about a social group. Participants responded on 6-point scales anchored with 1 'it appeals to thoughts and pieces of information' and 6 'it appeals to emotions and feelings'. The six items that we had selected for the affect-based evaluation were rated as more affect-related (and therefore less cognition-related, $M=4.89, S D=0.51)$ than were the six items selected for the cognition-based evaluation $(M=2.73, S D=0.55), F(1,19)=122.33, p<0.001 .^{2}$

The perceived similarity with the ingroup and the outgroup (manipulation check) was assessed by two questions ('Thinking about Italians to what extent do you feel they are similar to you?' 'Thinking about ... to what extent do you feel they are similar to you?') that were answered on a 6-point scale $(1=$ not at all, $6=$ extremely $)$.

\footnotetext{
${ }^{1}$ We selected two higher-status groups (i.e. Americans, $M=5.14, S D=0.79$, and Germans, $M=4.71, S D=0.84$ ) that differ in perceived likeability $(M \mathrm{~s}=4.47$ and $3.33, S D s=0.98$ and 0.66 respectively), $t(20)=4.72, p<0.001$, and two lower-status groups (i.e. Senegalese, $M=1.95, S D=0.49$, and Moroccans, $M=1.67, S D=0.48$ ) that differ in perceived likeability $(M \mathrm{~s}=3.00$ and 2.05, SDs $=0.89$ and 0.67 respectively), $t(20)=5.05, p<0.001$.

${ }^{2}$ The items were: interest, high regard, approval (cognition-based positive), uninterest, low regard, disapproval (cognition-based negative), liking, fun, attraction (affect-based positive), disliking, sadness, aversion (affect-based negative).
} 


\section{Procedure}

At the beginning of a lecture given by the first author, she introduced the confederate as a student allegedly from another university (and thus unfamiliar to the participants). Then a questionnaire was handed out and it took approximately 30 minutes for all participants to complete it. In the introduction to the questionnaire it was stated that the latter was part of an international investigation into the perception of foreigners and nationals among students of the European Union. It was explained at the outset that participants should give their perceptions of two national groups, their own (i.e. Italians) and one other group that was mentioned to them. Participants, therefore, knew the names of both target groups before they started to evaluate them. They were asked not to rate one specific person belonging to the target groups, but to give their impressions of these social groups in general. Initially, participants were asked to indicate their age, gender, and major subject. Subsequently, the first part of the questionnaire asked participants to rate one target group on a number of items. Then they were asked to rate the other target group on the same items. Finally, participants were asked to answer two questions about perceived similarity with the target groups (i.e. the ingroup and the outgroup). Answering these questions was counterbalanced for group order. Then, participants were debriefed and a summary of the aims and main results of the study was discussed with them in a following lecture.

\section{RESULTS}

\section{Manipulation Check}

In order to assess the effectiveness of the social categorisation manipulation, the scores for perceived similarity with the ingroup and the outgroup were subjected to an analysis of variance (ANOVA) with social categorisation (ingroup versus outgroup) as a within-participants factor. This analysis yielded a strong main effect for social categorisation, $F(1,112)=59.97, p<0.001$, such that participants perceived themselves more similar to the ingroup than to the outgroup $(M \mathrm{~s}=3.99$ and $2.98, S D s=0.92$ and 0.90 , respectively). This showed that the participants' social categorisation of the target groups coincided with that meant by the experimenters.

\section{Ambivalent Attitudes}

Participants' ratings of the target groups expressed on the positively and the negatively valenced items, although highly correlated (toward the ingroup: $r=-0.58$; toward the outgroup: $r=-0.51$ ), ${ }^{3}$ were not completely reciprocal. Therefore, both the computation of ambivalence scores and the separate exploration of the ratings on the two attitude domains appeared methodologically justified. Accordingly, unweighted mean scores were computed for affectively-based positive traits (target group: Ingroup, Cronbach's alpha $(\alpha)=0.69$; Outgroup, $\alpha=0.67$ ), affectively-based negative traits (Ingroup, $\alpha=0.66$; Outgroup, $\alpha=0.68$ ), cognitively-based positive traits (Ingroup, $\alpha=0.63$; Outgroup, $\alpha=0.68$ ), and cognitively-based negative traits (Ingroup, $\alpha=0.64$; Outgroup, $\alpha=0.72$ ).

We calculated ambivalence by using the formula proposed by Griffin and validated by Thompson et al. (1995) for use with close-ended measures. Unlike other formulae for calculating ambivalence (e.g. Katz \& Hass, 1988; Kaplan, 1972; for a contrastive review, see Thompson et al., 1995), this one

${ }^{3}$ The latter coefficient is the mean of the four outgroups' standardised scores. 
produces a score that is a function of the simultaneous intensity of the positive and negative ratings. Accordingly, we calculated ambivalence toward the ingroup and toward the outgroup by averaging the positive and negative attitude scores (both expressed by positive values) and subtracting the absolute difference between the two components from the average of the two components, using the formula $(\mathrm{P}+\mathrm{N}) / 2-|\mathrm{P}-\mathrm{N}|+1.5$, where $\mathrm{P}=$ positive attitude score, and $\mathrm{N}=$ negative attitude score. The constant of 1.5 was added in order to avoid negative results and obtain an ambivalence score of 0 when the positive and negative components were maximally different (possible range $=0$ to 7.5 ). For example, a positive attitude score of 4 and a negative attitude score of 1 would have resulted in an ambivalence score of -0.5 before the constant of 1.5 was added to make 1 . These calculations were performed for each attitude domain (cognition-based and affect-based).

Ambivalence scores were then subjected to a 2(target group: ingroup versus outgroup) $\times 2$ (attitude domain: cognition-based versus affect-based) within-participants ANOVA. The only main effect that was found is that of attitude domain, $F(1,115)=21.73, p<0.001$. Overall, participants expressed greater ambivalence on cognition-based $(M=4.13, S D=0.09)$ rather than on affect-based evaluations $(M=3.79, S D=0.08)$. Besides, the difference between ambivalence expressed toward the ingroup $(M=3.95, S D=0.09)$ and the outgroup $(M=3.98, S D=0.08)$ was minimal, $F<1$. The ANOVA also found a target group by attitude domain interaction, $F(1,115)=39.54, p<0.001$. In line with predictions, with respect to the cognition-based attitude domain, ambivalence was greater toward the ingroup rather than the outgroup, $t(115)=4, p<0.001$, while an opposite pattern was found with reference to the affective-based dimension of group evaluation, $t(115)=5.12, p<0.001$ (see Table 1). Moreover, ambivalence toward the ingroup was found to be greater along the cognition-based rather than the affect-based dimension of group evaluation, $t(115)=8.87, p<0.001$. In contrast, toward the outgroup the difference between ambivalence expressed along the two attitude domains was nonsignificant, $t<1$.

\section{Unipolar Ratings}

Positive and negative items were checked by a 2 (item valence) $\times 2$ (attitude domain) $\times 2$ (target group) within-participants ANOVA. The analysis revealed that overall participants expressed more polarised attitudes on positively valenced items $(M=2.99, S D=0.5)$ rather than on negatively valenced items $(M=1.53, S D=0.62, F(1,115)=232.98, p<0.001)$ and toward the ingroup $(M=2.48, S D=0.03)$ rather than toward the outgroup $(M=2.04, S D=0.04, F(1,115)=145.46, p=0.001)$. The difference between cognitive $(M=2.29, S D=0.03)$ and affective $(M=2.31, S D=0.04)$ items was only marginally significant, $F(1,115)=3.68, p<0.06$. All first-order interaction were also significant. ${ }^{4}$

Table 1. Mean ambivalence as a function of target group and attitude domain $(N$ of respondents $=116)$

\begin{tabular}{lcc}
\hline & Ingroup & Outgroup \\
\hline Cognition-based & $4.29_{\mathrm{a}}$ & $3.97_{\mathrm{c}}$ \\
& $(\mathrm{SD}=1.09)$ & $(\mathrm{SD}=1.14)$ \\
Affect-based & $3.58_{\mathrm{b}}$ & $3.99_{\mathrm{c}}$ \\
& $(\mathrm{SD}=1.19)$ & $(\mathrm{SD}=0.92)$ \\
\hline
\end{tabular}

Means with different subscripts differ from each others at least $p<0.001$ ( $t$-test).

\footnotetext{
${ }^{4}$ Valence $\times$ dimension, $F(1,112)=21.91, \quad p<0.001, \quad$ valence $\times$ group $, \quad F(1,112)=30.76, \quad p<0.001, \quad$ dimension $\times$ group, $F(1,112)=24.65, p<0.001)$.
} 
Table 2. Mean positive ratings as a function of target group and attitude domain $(N$ of respondents $=116)$

\begin{tabular}{lcc}
\hline & Ingroup & Outgroup \\
\hline Cognition-based & $4.16_{\mathrm{a}}$ & $3.72_{\mathrm{b}}$ \\
& $(\mathrm{SD}=0.65)$ & $(\mathrm{SD}=0.78)$ \\
Affect-based & $4.68_{\mathrm{c}}$ & $3.41_{\mathrm{d}}$ \\
& $(\mathrm{SD}=0.72)$ & $(\mathrm{SD}=0.88)$ \\
\hline
\end{tabular}

Means with different subscripts differ from each others at least $p<0.001$ ( $t$-test).

Table 3. Mean negative ratings as a function of target group and attitude domain $(N$ of respondents $=116)$

\begin{tabular}{lcc}
\hline & Ingroup & Outgroup \\
\hline Cognition-based & $2.72_{\mathrm{a}}$ & $2.56_{\mathrm{b}}$ \\
& $(\mathrm{SD}=0.77)$ & $(\mathrm{SD}=0.98)$ \\
Affect-based & $2.34_{\mathrm{c}}$ & $2.49_{\mathrm{b}}$ \\
& $(\mathrm{SD}=0.77)$ & $(\mathrm{SD}=0.98)$ \\
\hline
\end{tabular}

Means with different subscripts differ from each others at least $p<0.05$ (t-test).

More importantly for our hypotheses, these effects were qualified by the item valence $\times$ attitude domain $\times$ target group interaction, $F(1,115)=113.62, p<0.001$.

Follow-up analyses showed that, with respect to the positively valenced items (see Table 2), as expected, the ingroup was favoured over the outgroup both on the cognition-based dimension, $t(115)=8.8, p<0.001$, and on the affect-based dimension, $t(115)=25.4, p<0.001$. However, positive ratings toward the ingroup were stronger on the affect-based than on the cognition-based dimension, $t(115)=10.4, p<0.001$, while the opposite pattern was found with respect to the outgroup, $t(115)=6.2, p<0.001$.

With reference to negatively valenced items, means comparisons showed that the ingroup was, as predicted, favoured over the outgroup on the affect-based dimension, $t(115)=2.5, p<0.05$. An opposite pattern was found on the cognition-based dimension, $t(115)=2.67, p<0.01$. The latter result, however stronger than expected, appears to be in line with our prediction.

\section{DISCUSSION}

The present study was designed to explore the ambivalent evaluation processes targeting the basic 'social group' subtypes (namely, the ingroup and the outgroup) in intergroup contexts. We speculated that ambivalent attitudes could be a compromise strategy to cope with two apparently contrasting motivations, namely a) the social identity-based one of establishing positive distinctiveness for the ingroup in intergroup judgements (intergroup bias), and b) the normatively-based one of expressing non-prejudicially biased judgements toward the outgroup (fairness norm). In this regard we expected to find some asymmetries characterising affect- and cognition-based ambivalent attitudes targeting the ingroup and the outgroup that we posited to be related with the two above-mentioned needs to be satisfied by the individual as a group member (namely, maintaining positive social identity and normative conformity). Specifically, we predicted that no main effect of target group on ambivalence 
would be found, but rather an interaction of target group and (cognition-based versus affect-based) attitude domain on ambivalence. Additionally, since ingroup favouritism is more pronounced (and less visible) in the positive (versus negative) area (Mummendey \& Otten, 1998), we expected to find that when assessing positively valenced items, participants would express a more favourable evaluation of the ingroup rather than the outgroup in both cognition- and affect-based attitude domains. By contrast, when assessing negatively valenced items, we predicted that the ingroup would be favoured over the outgroup on affect-based evaluation (due to a weak activation of the fairness norm) but not on cognition-based evaluation (due to a stronger activation of the fairness norm).

Overall, our findings support the above hypotheses, thus permitting to draw some preliminary conclusions on the issue under investigation.

\section{Ambivalence versus Net Attitudes}

First, we found that positive and negative dimensions of participants' attitudes were correlated, but not completely reciprocal. Therefore it was possible for us to proceed under the safe premise that ambivalence was not equivalent to net attitude (as calculated by averaging the sum of positive dimension ratings and reverse-scored negative dimension ratings). In other words, this allowed us to specify separately the predicted effects on ambivalence and those on positive and negative attitude dimensions (i.e. favourability and unfavourability toward the target groups, respectively). The exclusive analysis of net attitudes highlights just a more positive evaluation of the ingroup relative to the outgroup (toward the ingroup: $M=4.45, S D=0.59$; toward the outgroup: $M=4.02, S D=0.73$, $F(1,113)=29.98, p<0.001)$ that can be identified both in the affect-based items (toward the ingroup: $M=4.68, S D=0.59$; toward the outgroup: $M=3.97, S D=0.74, F(1,115)=70.78, p<0.001)$ and in the cognition-based items (toward the ingroup: $M=4.22, S D=0.64$; toward the outgroup: $M=4.08$, $S D=0.80, F(1,113)=3.43, p<0.07)$.

Second, by comparing the results of parallel analyses, we showed that ingroup favouritism and ambivalence toward the ingroup vary according to which (cognition-based versus affect-based) attitude domain is used to measure them. Had this not been true, the ingroup favouritism that is active in intergroup evaluations should have yielded not only higher (i.e. more positive) overall net attitude ratings, but also lower ambivalent evaluations of the ingroup, relative to the outgroup. The fact that the latter was not the case empirically supports our argument that the issue of ambivalence in intergroup evaluations is worth studying inasmuch as it has the theoretical potentials, as we have shown, to generate some unique information over and beyond that allowed by the study of net intergroup attitudes.

\section{Implications, Limitations of the Study and Summary}

Our operationalisation of attitudes as cognition- versus affect-based has allowed us to underline a novel aspect of the positive-negative asymmetry in intergroup evaluation (Mummendey \& Otten, 1998 ) in that we showed that also the negative assessment may be biased in favour of the ingroup but only in the affectively based domain.

On the whole, our findings conceptually replicate and extend those of previous studies on the interplay between the above-mentioned competing socially based needs in intergroup attitudes (e.g. Bornstein et al., 1983a,b; Branthwaite \& Jones, 1975; Singh et al., 1998; Tajfel et al., 1971; Turner, 1983a,b). Ambivalence appeared to be a way to soften intergroup bias and express 'politically correct' attitudes. This strategy is primarily employed in cognition-based attitudes. Affect-based ingroup 
favouritism seems to be less prone to normative controls and, hence, affect-based attitudes toward the ingroup acquired a greater positive valence.

Since the aim of this study was simply the exploration of the different effects produced by intergroup context of evaluation on ambivalence, this is not yet a conclusive test of our interpretation of ambivalence as cognition-based control of the intergroup bias. In order to confirm the latter hypothesis, further research including measures or manipulation of endorsement of the fairness norm and social identity may be worth while.

Another limitation of the present study is the fact that the interaction effect was found with respect to a type of social categorisation (i.e. nationality) toward which social norms could allow for, if not promote, an affective preference for the ingroup. An obvious task for future studies is to investigate whether this effect is found also in intergroup contexts in which social norms control both the cognitive and the affective dimensions of ingroup favouritism (e.g. adults versus children, or non-blind people versus blind people).

In summary, despite these limitations, this research makes two important and novel contributions. First, our empirical evidence on ambivalence in intergroup context is largely in line with suggestions as formulated within the social identity approach to intergroup evaluation and behaviour. Second, the results provide novel, additional information on the significant role played by the affect- and cognition-based dimensions along which ambivalent (and unipolar) intergroup evaluations are formed and enacted.

\section{ACKNOWLEDGEMENTS}

This research was supported by Italian MURST grants (ex 40\%) to the first author. We would like to thank two anonymous reviewers for their helpful comments on an earlier version of this article.

\section{REFERENCES}

Allport GW. 1954. The Nature of Prejudice. Addison Wesley: Reading, MA.

Bargh JA, Chaiken S, Govender R, Pratto F. 1992. The generality of the automatic attitude activation effect. Journal of Personality and Social Psychology 62: 893-912.

Barker K. 1994. To be PC or not to be. A social psychological inquiry into political correctness. Journal of Social Behavior and Personality 9: 271-281.

Bornstein G, Crum L, Wittenbraker J, Harring K, Insko CA, Thibaut J. 1983a. On the measurement of social orientations in the minimal group paradigm. European Journal of Social Psychology 13: 321-350.

Bornstein G, Crum L, Wittenbraker J, Harring K, Insko CA, Thibaut J. 1983b. Reply to Turner's comments. European Journal of Social Psychology 13: 369-381.

Branthwaite A, Jones JE. 1975. Fairness and discrimination: English vs. Welsh. European Journal of Social Psychology 5: 323-338.

Breckler SJ. 1984. A comparison of numerical indexes for measuring attitudinal ambivalence. Educational and Psychological Measurement 54: 350-365.

Breckler SJ, Wiggins EC. 1989. Affect versus evaluation in the structure of attitudes. Journal of Experimental Social Psychology 25: 253-271.

Cacioppo JT, Berntson GG. 1994. Relationship between attitudes and evaluative space: A critical review, with emphasis on the separability of positive and negative substrates. Psychological Bulletin 115(3): 401-423.

Crano WD, Sivacek J. 1984. The influence of incentive-aroused ambivalence on overjustification effects in attitude change. Journal of Experimental Social Psychology 20: 137-158.

Deaux K. 1996. Social identification. In Handbook of Social Psychology, Kruglanski A, Higgins ET (eds). Erlbaum: Hillsdale, NJ; 777-798. 
Dovidio JF, Gaertner SL, Isen AM, Rust M, Guerra P. 1998. Positive affect, cognition, and the reduction of intergroup bias. In Intergroup Cognition and Intergroup Behavior, Sedikides C, Schopler J, Insko CA (eds). Erlbaum: Mahwah/London.

Duckitt J. 1992. Psychology and prejudice: An historical analysis and integrative framework. American Psychologist 4: 1182-1193.

Eagly AH, Chaiken S. 1993. The Psychology of Attitudes. Harcourt: Fort Worth, TX.

Ellemers N. 1993. The influence of socio-structural variables on identity enhancement strategies. European Review of Social Psychology 4: 27-57.

Fazio R, Zanna MP, Cooper J. 1977. Dissonance and self-perception: An integrative view of each theory's proper domain of application. Journal of Experimental Social Psychology 13: 464-479.

Fiske ST. 1998. Stereotypes, prejudice, and discrimination. In The Handbook of Social Psychology, Gilbert DT, Fiske ST, Lindzey G (eds). McGraw-Hill: Boston; 357-411.

Fiske ST, Ruscher JR. 1995. Negative interdependence and affect: Whence the affect? In Affect, Cognition, and Stereotyping, Mackie DM, Hamilton HM (eds). Academic Press: San Diego, CA.

Gaertner SL, Dovidio JF. 1986. The aversive form of racism. In Prejudice, Discrimination, and Racism, Dovidio JF, Gaertner S (eds). Academic Press: San Diego, CA; 61-89.

Glick P, Fiske ST. 1996. The Ambivalent Sexism inventory: Differentiating hostile and benevolent sexism. Journal of Personality and Social Psychology 70: 491-512.

Glick P, Fiske ST. in press. Ambivalent stereotypes as legitimizing ideologies: Differentiating paternalistic and resentful prejudice. In The Psychology of Legitimacy: Emerging perspectives on ideology, justice and intergroup relations, Jost JT, Major B (eds). Cambridge University Press: New York.

Glick P, Diebold J, Bailey B, Zhu L. 1997. The two faces of Adam: Ambivalent sexism and polarized attitudes among women. Personality and Social Psychology Bulletin 23: 1324-1334.

Haddock G, Zanna MP. 1999. Cognition, affect, and the prediction of social attitudes. European Review of Social Psychology 10: 75-99.

Haddock G, Zanna MP, Esses VM. 1993. Assessing the structure of prejudicial attitudes. The case of attitudes toward homosexuals. Journal of Personality and Social Psychology 65: 1105-1118.

Jonas K, Diehl M, Bromer P. 1997. Effects of Attitudinal ambivalence on information processing and attitudeintention consistency. Journal of Experimental Social Psychology 33: 190-210.

Jost TJ, Burgess D. 2000. Attitudinal ambivalence and the conflict between group and system justification motives in low status groups. Personality and Social Psychology Bulletin 26: 293-305.

Judd CM, Park B, Ryan CS, Brauer M, Kraus S. 1995. Stereotypes and ethnocentrism: Diverging interethnic perceptions of African American and White American youth. Journal of Personality and Social Psychology 69 : 460-481.

Kaplan KJ. 1972. On the ambivalence-indifference problem in attitude theory and measurement: A suggested modification of the semantic differential technique. Psychological Bulletin 77: 361-372.

Katz D, Hass RG. 1988. Racial ambivalence and value conflict: Correlational and priming studies of dual cognitive structures. Journal of Personality and Social Psychology 55: 893-905.

Katz I, Wackenhut J, Hass RG. 1986. Racial ambivalence, value duality, and behavior. In Prejudice, Discrimination, and Racism, Dovidio JT, Gaertner SL (eds). Academic Press: New York; 35-59.

Lavine H, Thomsen CJ, Zanna M, Borgida E. 1998. On the primacy of affect in the determination of attitudes and behavior: The moderating role of affective-cognitive ambivalence. Journal of Experimental Social Psychology 34: 398-421.

Linville PW, Fischer GW, Salovey P. 1989. Perceived distributions of the characteriestics of ingroup and outgroup members: Empirical evidence and a computer simulation. Journal of Personality and Social Psychology 57: 165-188.

MacDonald TK, Zanna MP. 1998. Cross-dimension ambivalence toward social groups: Can ambivalence affect intentions to hire feminists? Personality and Social Psychology Bulletin 24: 4, 427-441.

Mackie DM, Smith ER. 1998. Intergroup relations: Insights from a theoretically integrative approach. Psychological Review 105: 499-529.

Maio GR, Bell DW, Esses VM. 1996. Ambivalence and persuasion: The processing of messages about immigrant groups. Journal of Experimental Social Psychology 32: 513-536.

McConahay JB. 1983. Modern racism and modern discrimination: The effects of race, racial attitudes, and context on simulated hiring decisions. Personality and Social Psychology Bulletin 9: 551-558.

McConahay JB, Hardee BB, Batts W. 1981. Has racism declined in America? It depends on who is asking and what is asked. Journal of Conflict Resolution 25: 563-579. 
McConahay JB, Hough JC Jr. 1976. Simbolic racism. Journal of Social Issues 32: 23-45.

Messick DM, Mackie DM. 1989. Intergroup relations. Annual Review of Psychology 40: 45-51.

Monteith MJ. 1993. Self-regulation of prejudiced responses. Implications for progress in prejudice reduction efforts. Journal of Personality and Social Psychology 65: 469-485.

Mucchi-Faina A. 2000. Minority influence and ambivalence. Revue Internationale de Psychologie Sociale 15: 65-87.

Mullen R, Brown RJ, Smith C. 1992. Ingroup bias as a function of salience, relevance, and status. An integration. European Journal of Social Psychology 22: 103-122.

Mummendey A, Otten S. 1998. Positive-negative asymmetry in social discrimination. European Review of Social Psychology 9: 107-143.

Osgood CE, Suci GJ, Tannenbaum PH. 1957. The Measurement of Meaning. University of Illinois Press: Urbana, IL.

Pettigrew TF. 1997. Generalized intergroup contact effects on prejudice. Personality and Social Psychology Bulletin 23: 173-185.

Pettigrew TF, Meertens RW. 1995. Subtle and blatant prejudice in western Europe. European Journal of Social Psychology 25: 57-75.

Phinney JS. 1990. Ethnic identity in adolescents and adults: A review. Psychological Bulletin 108: 499-514.

Pomerantz EM, Chaiken S, Tordesillas RS. 1995. Attitude strength and resistance processes. Journal of Personality and Social Psychology 69: 408-419.

Scott WA. 1966. Brief report: Measures of cognitive structures. Multivariate Behavioral Research 1: $391-395$.

Scott WA. 1969. Structure of natural cognitions. Journal of Personality and Social Psychology 12: 261-278.

Sears DO. 1988. Symbolic racism. In Eliminating racism: Profiles in controversy, Katz PA, Taylor DA (eds). Plenum Press: New York; 53-84.

Singh R, Mei Choo W, Li Poh L. 1998. Ingroup bias and fair-mindedness as strategies of self-presentation in intergroup perception. Personality and Social Psychology Bulletin 2: 147-162.

Singh R, Yeoh BE, Lim DI, Lim KK. 1997. Cross categorization effects in intergroup discrimination: Adding versus averaging. British Journal of Social Psychology 36: 121-138.

Tajfel H, Billig MG, Bundy RP, Flament C. 1971. Social categorization and intergroup behaviour. European Journal of Social Psychology 1: 149-178.

Tajfel H, Turner JC. 1979. An integrative theory of intergroup conflict. In The Social Psychology of Intergroup Relations, Austin WG, Worchel S (eds). Brooks/Cole: Monterey, CA.

Tetlock PE, Levi A. 1982. Attribution bias: On the inconclusiveness of the cognition-motivation debate. Journal of Experimental Social Psychology 18: 68-88.

Thompson MM, Holmes JG. 1996. Ambivalence in close relationships: Conflicted cognitions as a catalyst for change. In Handbook of Motivation and Cognition: Foundations of social behavior, Sorrentino RM, Higgins ET (eds). Guilford: New York; 479-531.

Thompson MM, Zanna MP. 1995. The conflicted individual: Personality-based and domain-specific antecedents of ambivalent social attitudes. Journal of Personality 63: 259-288.

Thompson MM, Zanna MP, Griffin DW. 1995. Let's not be indifferent about (attitudinal) ambivalence. In Attitude Strength: Antecedents and consequences, Petty RE, Krosnick JA (eds). Erlbaum: Mahwah, NJ; 361-386.

Turner JC. 1983a. Some comments on Bornstein, Crum, Wittenbraker, Harring, Insko, \& Thibaut's 'The measurement of social orientations in the minimal group paradigm'. European Journal of Social Psychology 13: $351-367$.

Turner JC. 1983b. A second reply to ... 'The measurement of social orientations in the minimal group paradigm'. European Journal of Social Psychology 13: 383-387.

Turner JC. 1987. Rediscovering the Social Group: A self-categorization theory. Blackwell: Oxford.

Vescio TK, Hewstone M, Crisp RJ, Rubin JM. 1999. Perceiving and responding to multiply categorizable individuals: Cognitive processes and affective intergroup bias. In Social Identity and Social Cognition, Abrams D, Hogg MA (eds). Blackwell: Oxford; 111-140.

Yee MD, Brown R. 1992. Self-evaluations and intergroup attitudes in children aged three to nine. Child Development 63: 619-629.

Wenzel M, Mummendey A. 1996. Positive-negative asymmetry of social discrimination: A normative analysis of differential evaluations of ingroup and outgroup on positive and negative attributes. British Journal of Social Psychology 35: 493-507.

Zanna MP, Rempel JK. 1988. Attitudes: A new look at an old concept. In The Social Psychology of Knowledge, Bar-Tal D, Kruglanski AW (eds). Cambridge University Press: Cambridge; 315-334. 